\title{
Harald Wohlrapp
}

Würzburg: Königshausen und Neumann, 2008. Pp. xvi + 527. ISBN 978-38260-3820-4. €49.80.

Argumentation scholars rarely see a work added to the literature in their field comparable in magnitude and merit to Harald Wohlrapp's new book. It looks like a medium-sized blue brick and is the fruit of about twenty years of thinking, discussion and teaching. Wohlrapp sees our present situation as one where, over the last century, the concept of truth has been progressively 'eroded', from Einstein's overthrow of Newton to Kuhn and post-modernism. A theory of argument is needed which duly recognizes the dynamic, ever-evolving nature of human understanding and also the reality of separate, subjective frames of reference, but at the same time avoids crass relativism. What is the role and nature of argument in this environment, and what makes an argument 'valid'? He rejects the traditional, dichotomous definitions of good argument - the logical one, which demands true premisses entailing true conclusions, and the rhetorical one, which (as he sees it) posits mere acceptance as its criterion. A fragment from the pre-Socratic philosopher Xenophanes is placed as the book's motto: dokos d'epi pāsi tetuktai, which I believe means something like "(mere) guesswork/opinion is allotted to all"; if this is the point of departure, then how to put the theory of argumentation on a philosophical footing that is not merely relativistic?

Wohlrapp's proposes a 'pragmatic' approach to what argument does: It provides us with theories, whose purpose is to serve as orientations in the world. Argument builds on what we take to be knowledge, or epistemic theory, 'old' theory', in order to project new theory, thetic theory. What validates a thetic theory, i.e., what makes it a valid orientation, is that it shows itself to be 'successful' in dealing with the world. Thetic validity is thus the property of being suitable to serve as a new orientation. A theory is thetically valid so long as it works, i.e., so long as we are successful in building on it, so that it fills what used to be an 'orientation gap' for us.

Thus Wohlrapp aims to avoid the pitfalls of seeing validity as either immutable logical validity, or as mere acceptance (he tends to see this as the 'rhetorical' definition of validity, thus applying a common philosophical understanding of what rhetorical argumentation is to which many rhetoricians, including myself, would object). He illustrates his concepts generously with cases in point drawn from history, ethics and science - such as the theory of phlogiston, a substance was once thought to inhere in some materials and to be 'liberated' in combustion. This 
theory was a valid orientation for science for in explaining the nature of fire and other phenomena for quite some time, but only until Lavoisier demolished it in 1783. This exemplifies how understanding, driven by argument, is dynamic and under constant revision in an ongoing dialogue with the current 'state of the argument' at any time. The kind of process envisaged by Wohlrapp can, he submits, explain the step-by-step progression of science in creative dialogue in a way that Kuhn's 'incommensurability' thesis, sharpened and oversold by Feyerabend, cannot.

Wohlrapp's own orientation in contemporary argumentation theory as well as in several branches of philosophy is apparent throughout - not something you could say for all philosophers who specialize in argumentation theory. Current trends and prominent thinkers in our field are completely familiar to him, and he presents nuanced assessments of them. For example, he is respectful of the high theoretical awareness and synthesizing drive of the pragma-dialectical school, yet he finds its view of argumentation, as aiming at the resolution of dispute between two arguers, too 'unambitious": "what's lacking in Amsterdam is a pragmatically secured concept of theory that can be taken seriously" (41); that is, like Harvey Siegel and others, he regrets the lack of a concept of validity over and beyond the interlocutor's acceptance. This is the gap that he tries to fill with his concept of 'orientation'. Pragmadialectics, he holds, is neither pragmatic enough nor dialectical enough: it does not account for differences of 'frames' or perspective, i.e., the fact that one and the same issue may appear as one thing from a given perspective and as quite another from a different one. Such differences in regard to the question 'What are we discussing?' are precisely the sort of thing that sets off the most heated disputes, and argumentation theory must ways of handling such differences of perspective, since they belong to the very core of a dispute, whereas, according to pragma-dialectics, they should be have set aside in the 'Opening Stage', securing the ground rules for the following 'Argumentation Stage'.

Another provocative discussion centers on Trudy Govier's treatment of 'conductive reasoning'. Wohlrapp rightly singles out Govier as perhaps the only theorist who has considered the situation where there are relevant reasons both pro and con, and where 'weighing' seems called for. Yet he is dissatisfied with the way Govier stops short of providing a decision procedure for the dilemmas she has discussed. He is, I believe, right to dismiss a suggestion made by Govier for how to 'weigh' principles speaking for contradictory conclusions, namely that those principles to which there are the fewest exceptions (under a 'ceteris paribus' clause) have most weight: there is no way of actually counting these exceptions, which are in principle an open set. Wohlrapp is generally sceptical of the notion of 'weighing' pro and con reasons. That term casts a deceptive appearance of objectivity over the process and glosses over the fact that individuals may see the same 'facts' in different 'frames'-which, in turn, give them different 'weights'. The confron- 
tation of contradictory reasons, he points out, is not a static affair. Reasons may call forth counter-reasons and be transformed in the confrontation with them. Divergent frames may be integrated. Wohlrapp very usefully lists four ways in which this may happen. One frame may substitute another; divergent frames may be placed in a hierarchy; they may be shown to be compatible with each other in a kind of compromise; or they may be synthesized so that both are suspended in favor of a third frame which neutralizes the contradiction between them.

Wohlrapp's acute awareness of the problems of conflicting frames, and his definitions and demonstrations of these operations constitute a great asset of the book. He brings all four operations to bear on a significant case in point, namely the debate over legalization of euthanasia for terminally ill patients who wish to die. On the face of it, this debate seems to be clear case of conductive reasoning, but Wohlrapp's aim is to show that a careful process of confrontation of the contradictory reasons and frame integration does not leave the issue undecided, but actually produces a valid orientation: such euthanasia, at the present 'stand of the argument', should not be legalized. A decisive reason, brought forth in the dynamic process just described, is that relatives, under such a law, would be able pressure terminally ill patients to opt for euthanasia, thus in fact compromising their freedom of choice rather than extending it.

Wohlrapp's reasoning here is very incisive and perceptive, yet I take exception to the implied suggestion that, with reasons both pro and con, critical analysis can nevertheless find the valid orientation. To my mind, he is right in dismissing Govier's rather sketchy method for weighing contradictory reasons in a 'trans-subjective' manner, as he would call it, but I think the appropriate conclusion is that no such method existsnotwithstanding the fact that Wohlrapp's argument analysis clearly makes us wiser. Or does he really think a philosophically based argumentation theory can determine what the valid orientation is regarding, e.g., legalisation of euthanasia? This is where I recoil, as I do over a different passage, in Wohlrapp's critique of pragma-dialectics, where he asks, rhetorically: "Where is the method of argument with which we determine, e.g., that research on embryos ought only to be legal with restrictions, or that the republic is more in keeping with human dignity than monarchy?" (40). My answer would be: That method is nowhere. Or is argumentation analysis to provide valid orientations on all the vexed and contentious issues over which legislators and citizens in modern societies disagree? In that case, why not call in the argumentation analysts to decide whether we ought to have monarchy and legal abortions and public health care and progressive taxation (and if so, how progressive, and what the general level of taxation should be)? But how does Wohlrapp's assumption that argumentation analysis can tell us which orientations on moral and political issues are valid differ from the Platonic ideal of a state where philosophers determine what is right for all and democracy is dispensed with? Isn't it rather that 
argument analysis and criticism can could provide individuals with a qualified basis for making up their minds, possibly for changing them; or should argument analysts also make up our minds for us?

Wohlrapp is certainly not the kind of authoritarian thinker who would consciously take such a stance. But the problem in my view is that he sees the human need for 'trans-subjectively' valid 'orientations', fighting off relativism, as operative not just in regard to describable states of affairs, but also in regard to evaluative norms and norm-based decisions as well; and he is aware that this disregard of the distinction between facts and norms may be provocative (164). His point is that in both fields, the orientations on which we rely must 'function'; for example, huge differences between rich and poor in a society "will not do", because they will lead to cynicism in the rich and crime in the poor. So norms for what is good and bad, in morals and in politics, are, according to Wohlrapp, essentially 'theories' subject to the same pragmatic kind of validation as are theories about the state of the world: they acquire thetic validity by being 'successful' in application.

Wohlrapp is very aware of the role of subjectivity in argumentation and maintains, rightly in my view, that "so far we have no adequate conceptual instruments for understanding the subjective in argumentation" (149). Yet his own account of subjectivity, though sensitive and thoughtful, tends to se subjectivity only as a general condition of human action, communication and argumentation; he seems to have little room in his theory for individual differences between subjects. Such differences, he seems to believe, should ideally be eliminated by the meticulous, dynamic confrontation of pro and con reasons and the application of frame-integrative procedures. Now these procedure, as defined and demonstrated by Wohlrapp, could no doubt result in better mutual understanding, workable compromises, sometimes even consensus and at least meta-consensus (as defined by political theorist John Dryzek) on many contentious social issues; but there is little in his book about legitimate subjective differences between individuals, e.g., regarding the relative priority assigned to given evaluative considerations. Even if incompatible frames are brought into harmony so that pro and con reasons can be related to each other, we would often find that arguer A finds the reason $\mathrm{R}$ much more important than does arguer $\mathrm{B}$, who recognizes $\mathrm{R}$, but finds that $\mathrm{Q}$ clearly outweighs it; and no analytical bystander would be able to determine who is 'right'. Such subjective differences help explain the fact that some people prefer a society with low taxes and few welfare programs, while others prefer higher taxes and comprehensive welfare.

Does Wohlrapp advocate a theory of argumentation according to which argument analysis can determine which of these two political views is the valid one? Of course any theory implying such a presumption would be a fond illusion. No theory or philosophy can determine such questions for us: they are ultimately matters of choice, and as Aristotle says in the Eudemian Ethics, "choice [proairesis] is 
neither true nor false". Where there is choice, people will always choose differently, although argument may influence the choice of some people; that is why, in democracies, matters like taxation, or the legalization of euthanasia, are decided by majority rule, and that is also why there is, or should be, public argument.

Wohlrapp is an independent and original thinker who wants to belong to no school, but has a broader intellectual scope than existing schools. In true Aristotelian manner, he presents a sane and balanced theory based on observation and reflection rather than on axioms. But I question his desire to present a unified theory that downplays the distinction between facts and norms; while an individual cannot have his own individual facts that differ from other people's facts, he can have his own individual norms which in turn dispose him for his individual choices. In his attempt to counter what he sees as 'rampant relativism' of our time Wohlrapp sometimes seems to me to throw out the baby, choice, with the relativistic bath water. What alarms him about the relativism he sees around him is "the belief that, at the end of the day, arguing is useless" (6). But there is no need to believe that arguing is useless even if we abandon the idea that argumentation theory can dictate our moral and political choices. There has always been and always will be argument about issues where choice is possible. That kind of argument is what I understand by 'rhetoric'. We need thinkers like Wohlrapp to theorize such argument.

On a concluding note, it deserves mention that Wohlrapp writes a kind of prose widely different from what we expect, perhaps unjustly, from academic German: it is less formal, less hypotactic, less leftbranching, less burdened by impersonal passives and nominalizations, more supple and conversational, with more of a personal ethos coming out from the pages; it has more of the engaging rhetorical qualities reminiscent of the Socratic dialogues or the best of moral and analytical philosophy written in English. It is not necessarily briefer of more succinct than the stiffer varieties of academic German: In fact, had Wohlrapp decided to let result of twenty years of thought and discussion simmer on the stove for another year or two, he might have boiled it down to 400 or even 300 pages; indeed, he declares in the preface that he would have liked to. But the community of argumentation theorists should be grateful that a full and authoritative presentation of Wohlrapp's thinking is finally available. His ambition is to lay a better philosophical foundation for the theory of argument, no less; as someone who believes that the currently dominant philosophical theories have unsustainably narrow foundations, I think something like Wohlrapp's pragmatic account is a overdue corrective influence, and that argumentation theorists owe it to themselves to learn from it. 